This item was submitted to Loughborough's Research Repository by the author.

Items in Figshare are protected by copyright, with all rights reserved, unless otherwise indicated.

\title{
Using a smartphone 'app' in qualitative research: the good, the bad and the ugly
}

PLEASE CITE THE PUBLISHED VERSION

http://dx.doi.org/10.1177/1468794115593335

PUBLISHER

SAGE Publications

VERSION

AM (Accepted Manuscript)

\section{PUBLISHER STATEMENT}

This work is made available according to the conditions of the Creative Commons Attribution-NonCommercialNoDerivatives 4.0 International (CC BY-NC-ND 4.0) licence. Full details of this licence are available at: https://creativecommons.org/licenses/by-nc-nd/4.0/

\section{LICENCE}

CC BY-NC-ND 4.0

\section{REPOSITORY RECORD}

Garcia, Borja, Joanna Welford, and Brett M. Smith. 2019. “Using a Smartphone 'app' in Qualitative Research: The Good, the Bad and the Ugly". figshare. https://hdl.handle.net/2134/18340. 
Using a smartphone 'app' in qualitative research: The good, the bad and the ugly

Borja García, Jo Welford and Brett Smith

Borja García (corresponding author): Lecturer in Sport Management and Policy, School of Sport, Exercise and Health Sciences, Loughborough University, Leicestershire, LE11 3TU, UK. b.garcia-garcia@lboro.ac.uk

Jo Welford, Research Associate (FREE Project), School of Sport, Exercise and Health Sciences, Loughborough University, UK. j.welford@lboro.ac.uk

Brett Smith, Reader in Qualitative Health Research, School of Sport, Exercise and Health Sciences, Loughborough University, UK. b.m.smith@lboro.ac.uk 
Using a smartphone app in qualitative research: The good, the bad and the ugly

\begin{abstract}
This paper reflects on the use of a smartphone application ('app') in qualitative research following the experience of the FREE (Football Research in an Enlarged Europe) project, which investigated the lives of football fans in the UK. To meet this aim, a participant-focused audio-visual methodology was designed, featuring the use of an app to collect data. Fans were asked to take photographs and keep diaries to show the role football plays in their lives. The smartphone app was developed to allow fans to use their own mobile phones, capturing qualitative data in 'real time'. The paper reflects on our experience of using the smartphone app in this qualitative research, analysing the advantages, disadvantages and the main risks that researchers will need to take into account when using smartphone apps in their future qualitative research projects. We encourage others to build on and advance this underresearched but potentially valuable tool.
\end{abstract}

Keywords: smartphone app; mobile phone; iPhone; android; audiovisual methods; auto-ethnography; qualitative research; digital divide; technology; football 
Introduction: Mobile Phones, Smartphones and Applications in research

Smartphones - defined as programmable mobile phones - are widely used in Western countries (Raento, Oulasvrite and Eagle, 2009) and continue to increase their market share. For example, in the UK smartphones were owned by over $60 \%$ of the population at the end of 2013 with ownership projected to rise to over 80\% by 2017 (We Are Apps, 2013). For the 16-64 age range, smartphone ownership in 2013 was 72\%, a figure that rose from 58\% only ten months previously (Deloitte, 2013). Similar figures are suggested for the USA (Edison Research, 2014; Pew Research, 2014).

Applications are software programmes that run on smartphones (Patel et al, 2013), enhancing the functionality of larger programmes and allowing them to run in a userfriendly way that is designed for the mobile phone screen. Smartphones and apps are not used widely in research presently, and where they have been utilized it has mainly been to collect quantitative data such as demographics (Aanensen et al, 2009; Kiukkonen et al, 2010; Raento et al, 2009), time use (Bouwman, Heerschap and de Reuver 2013; Sonck and Fernee, 2013), market research (Chen, 2011), monitoring human behaviour and interactions (Dennison et al, 2013; Luxton et al, 2011; Payne, Wharrad and Watts, 2012), plotting feelings in relation to location (Killingsworth and Gilbert, 2010; MacKerron and Mourato, 2013) and gathering observational data (Patel et al, 2013).

The use of smartphones in qualitative research however is absent in the academic literature, which is a notable gap given the increased use of interactive methods such as diaries and photography. Reflecting on how technology may encourage future 
opportunities for diary-based research a decade ago, Bolger, Davis and Rafaeli (2003: 599) suggested that improved mobile communication allows online, duplex (i.e., interactive) contact with participants. For example, researchers can now send questions to, and receive responses from, participants in real time'. Diary-based methods have not generally followed advances in technology, with empirical studies still overwhelmingly providing participants with audio or video equipment (see for example Cherrington and Watson, 2010; Tamminen and Holt, 2010; Williamson et al, 2011) or maintaining the written format (see for example Day and Thatcher, 2009; Duke, 2012). One example where advances in technology have been utilised in audiovisual methods is Plowman and Stevenson's (2012) study that collected qualitative data by asking parents to use their mobile phone to take and send images for a family time use study.

\section{Why use smartphones to collect data?}

Previous quantitative studies that have utilised mobile phone technology have described a number of benefits of this approach. The use of smartphones can be a time and cost-effective solution (Dennison et al, 2013; Raento, Oulasvirta and Eagle 2009), particularly as a large (and remote) sample size is possible (Kiukkonen et al, 2010; MacKerron and Mourato, 2013; Patel et al, 2013). Another benefit is that longitudinal studies are also more feasible as once downloaded, the app can be used over time (Chen, 2011; MacKerron and Mourato, 2013). Efficiency is further enhanced by the instant transfer of data (Patel et al, 2013; Sonck and Fernee, 2013). Smartphone 
apps are interactive and user-friendly, which can improve the response rate and reduce drop-out (Chen, 2011; Plowman and Stevenson, 2012) as interest can be sustained longer (Dennison et al, 2013).

Aside from these practical benefits, the trialling of apps in research has produced data that can be both immediate and encompass changes over time. A broader range of quantitative data, such as what people are doing at a certain point of time (Aanensen et al, 2009; Kiukkonen et al, 2010) can be supplemented with accurate and reliable location information, allowing data to be understood in its context (Chen, 2011; Dennison et al, 2013; MacKerron and Mourato, 2013). This can give an insight into not just what people are doing but where and when they are doing it. Images can be uploaded to give further contextual information (Plowman and Stevenson, 2012).

Researchers have also suggested the benefits of mobile technology to participants. Using an app contained within a mobile phone is unobtrusive and discrete (Kiukkonen et al, 2010; Raento, Oulasvirta and Eagle, 2009), particularly useful if the research topic is sensitive (Dennison et al, 2013). Equipment does not need to be provided and is familiar to the participant (Dennison et al, 2013; Sonck and Fernee, 2013). If an app is used to replace other tools such as online surveys, participants do not need to be by their computer to take part (Patel et al, 2013; Sonck and Fernee, 2013). All these make retention more likely. 


\section{Identifying a gap: smartphones and qualitative research}

As previous studies have dominantly collected quantitative data, the potential of the smartphone for qualitative researchers is yet to be fully explored. This absence is notable, as smartphones by their very nature and interactive design are extremely capable of collecting and even generating qualitative data. Smartphones have integrated cameras, can record video and audio clips, and allow these to be shared instantly in a variety of ways. But with little in the academic literature to guide the qualitative researcher, it might seem like venturing into the unknown.

Set against this background, the purpose of this paper is to outline and reflect on the process of using smartphone app to collect qualitative data in a research project that explored the lives of football fans. Having reviewed the available literature around the use of smartphone apps in research, the article proceeds in three steps. First, we contextualise the decision to use an app within the wider study of the project. Second, the article reflects upon the challenges, weaknesses and strengths of using a smartphone app for qualitative research. To conclude, we offer some suggestions from our own experience for those considering using an app. It is hoped that this paper will begin to address a question that is as yet unanswered: Are the benefits of using a smartphone app in quantitative research equally applicable to qualitative methods? 


\section{Research context: The FREE project and the use of a smartphone app}

The FREE (Football Research in an Enlarged Europe) ${ }^{1}$ Project is a pan-European study investigating the role that football plays in the daily lives of supporters. It was conceived around audiovisual methods, as participants were asked to produce a number of photographs and audio-diaries to document their football experiences. 37 participants were asked to take pictures of their involvement in football and keep an audio diary linked to four football-related events over an eight week period. Following this, a photo elicitation interview with each participant was done to allow them to explain and interpret their images (Sparkes and Smith, 2014).

Early on in the design of the project it was envisaged that calls for greater diversity of qualitative research methods could begin to be answered by integrating smartphone use into the planned audio-visual methods. But how would this work in practice? Whilst cognisant of the digital divide, most people (93\% at Q1 2014) in the UK own a mobile phone (Ofcom, 2014). One option was to ask fans to use their phone to take photos and send them to us, as used successfully by Plowman and Stevenson (2012). The decision was made to investigate the possible use of an application that participants could download onto their smartphones. The reasons for deciding to use an app were threefold: (i) To make the process of collecting data simple for the participants, (ii) to make participating in the project fun and interactive, (iii) to encourage participants to capture their lives in real time.

We approached a local software company who had experience in designing apps for research, and worked with them. The decision was made to develop the data 
collection tool by tailoring an existing app, rather than creating a new one. This was deemed an acceptable compromise of flexibility and financial outlay, but was not without consequence, as discussed below.

\section{The design and use of the app}

Designing the app involved a number of decisions that could have a great impact on the type, quality and amount of data collected. Sonck and Fernee (2013) support the need for reflection during the app design process, stressing the importance of elaborating more on these decisions due to the infancy of the field. For us, working with a software company was extremely useful as they could advise on the type of question format that had been used successfully before and worked well on the small screen. Designing the app content involved writing a 'script' on paper, in a similar way as a questionnaire would be designed, considering not only the wording of the questions, but also the flow of the different activities and questions.

\section{The structure of the FREE project app}

The decision was made to structure the app into four sections, aligned with the methods for the project. The two main tasks, the photograph album and audio-diary, were preceded by an introductory task; we also added an optional 'anytime' task. The design of the app therefore involved translating the planned audio-visual methodology onto the smartphone screen, with some modification for ease of use. Adding an 
introductory task allowed for familiarisation with the app and the collection of demographic and other data, and finishing with an 'anytime' task was at the suggestion of the software company to give one open and flexible upload option.

Introductory task: this was the only option available when participants first downloaded the app, and therefore had to be completed before any other activities. The purpose of the introduction was to collect information about the participant such as age, gender and location as well as details about their support of football. The primary aim of this task was to allow the participants to get to know the app, as well as to make sure that there were no technical problems before starting the real time of data collection.

Once the introductory task had been completed, the other activities were unlocked and participants could see a home screen with the picture, diary and anytime activities (see figure 1 below). 
Figure 1. The FREE Project app's homescreen

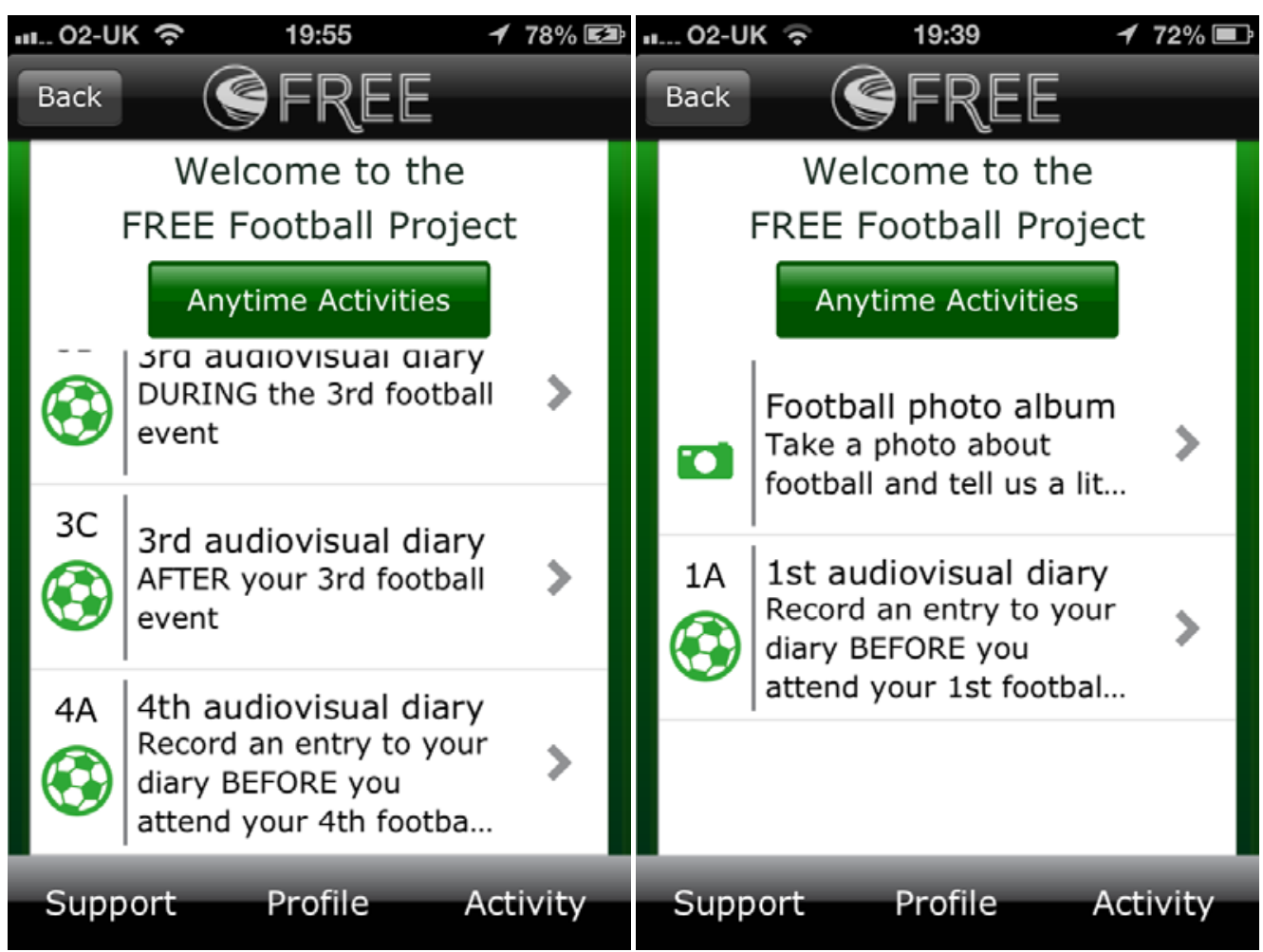

Football photo album: To submit a photograph, participants had the option of taking a photo with the camera from within the app, or selecting an existing one from their phone picture gallery. Once the image had been selected, participants were then asked to give it one or two of five predetermined categories or 'tags'. It was decided that the photography task required a minimal structure in order to align the data collection with our original research questions, give some consistency to the data uploaded and ensure that findings could be related to existing research in the area. Five predetermined tags were devised following an extensive review of the academic literature on football supporters: 


\section{Sharing football experiences \\ 2. My own involvement in football \\ 3. The state of football today \\ 4. Football traditions \\ 5. What football means to me}

Participants also had the option to tag the image with 'no category', giving flexibility and preventing participants from feeling that they needed to fit an image to a particular category if they felt it did not belong to any.

All images were followed by the question 'how would you mark the importance of this photograph to you?' and given a sliding scale of one to ten. This was included to rank the photographs, an attempt to select the most significant photographs prior to the photo-elicitation interview. Participants were then were asked one or two questions about their image depending on what tag they gave it. Finally there was an optional text box for comments about the image, allowing for open ended answers.

Audio-visual diary: Participants were asked to record diaries around four events, and they had the option to do a video or an audio entry. For each event they were asked to record their thoughts the day before, the day of each event and the day after. The app was designed in a way that participants could only record an entry if the previous one had been uploaded. This activity was simple, as participants had only to press a button to start and finish recording their entry. Once they were happy, they had to press another button to upload the file (See figure 2 below). 
Figure 2. Screenshot of the audio/video diary task

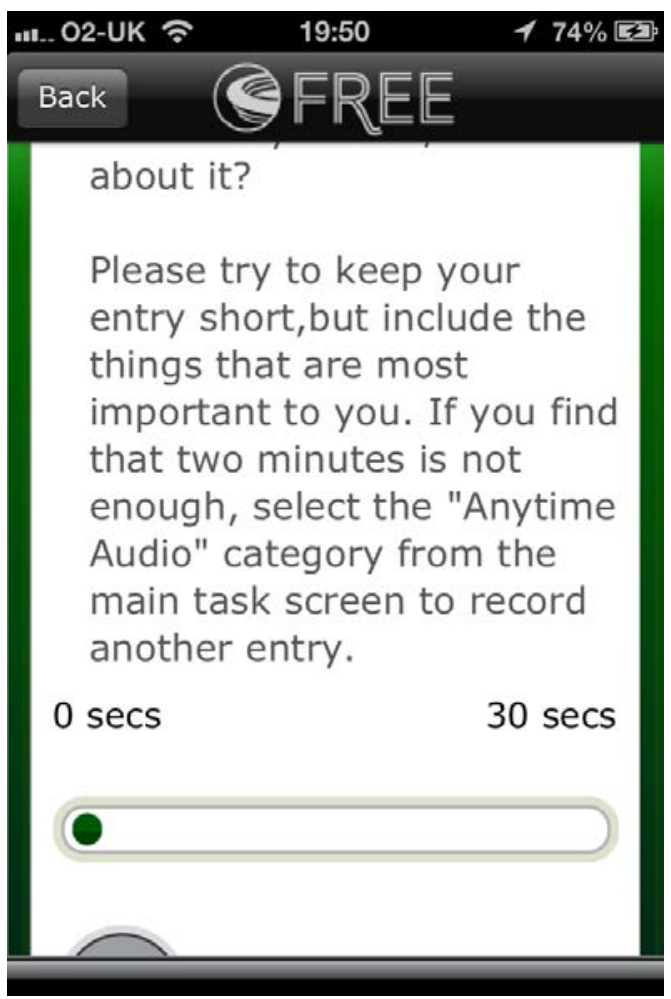

The app automatically processed the diary entry, tagging it with the date and time when it was recorded.

Anytime activity: Here, users could upload a photograph, audio clip, video clip or text entry instantly. Being able to upload data in this way offered a quick method of submission of all file types. A text box was deemed useful for any quick comment that participants might want to make, and provided an essential alternative option for those uncomfortable with or unwilling to record audio diaries, responding to the call 
for choice to be given to participants wherever possible (Bolger, Davis and Rafaeli, 2003).

\section{Participant recruitment}

The major decision at the recruitment stage was whether to open the project up to participants who did not own a smartphone. We decided not to mention the app in the recruitment material. The audio visual methods were described and participants were told that they could use their own equipment for taking photographs and recording audio or be provided with it. Once football supporters had registered their interest in the project, they were asked if they owned a smartphone. If so, they were informed about the app. Interestingly, even though the call for participants was mostly done online, only two thirds were able to or elected to use the app, reflecting current debates over the digital divide - a gap still exists between internet access and smartphone ownership (and usage).

Participants were recruited through online calls via various football media including national and European supporter organisations, individual teams' supporter clubs and media contacts. These calls were widely distributed, mainly on-line, in the United Kingdom and other European countries thanks to the networks of the research team. Those interested signed up and gave basic demographic details as well as information about their football interest. As we always intended to recruit what we considered as 'heavily engaged' football fans, we wanted to ensure that participants had a significant interest and investment in football. This form of purposive sampling necessitated the 
selection of individuals or groups to provide 'information rich' cases to answer the research questions (Patton, 1990; Sparkes \& Smith, 2014). From those who volunteered, we selected participants on the basis of their football interest and to give a cross-section of football supporters in terms of gender, age and level of club supported.

\section{App-generated data}

To give an idea of the data that was collected via the app, we present here a small amount of data that was generated by one of the participants using the app. A fully fledged presentation of the data is beyond the scope of this paper, ${ }^{2}$ but with this section we hope to give a flavour of how the app was used in practice, in order to consider the validity and reliability. As discussed below, we feel that this demonstrates the mobile nature of this data collection tool and the potential for rich real-time submissions.

Figure 3 (below) presents visual data generated as part of the 'photograph album' task. These are three images submitted by the participant, and the follow-up information provided as a response to in-app prompts and questions. It also includes, briefly, part of the discussion of each picture in the follow-up interview. All these images were taken at football matches, demonstrating the usability of the app for capturing this type of data during normal football-related activities.

\footnotetext{
${ }^{1}$ Please see www.free-project.eu for more details about the FREE Project.

${ }^{2}$ Welford, Garcia and Smith (2015) gives a more in-depth discussion and analysis of the audio-visual data collected by football supporters - both those who used the app and those who did not.
} 
Figure 3: Example of data gathered through the photograph album task




The second task asked participants to record diary entries before, during and after an event. Besides the diary, participants could keep taking and submitting pictures. That is to say, both activities could be done in parallel. Figure 4 (below) gives an example of one event that constituted the diary on the same participant as above. Here, the figure presents both a small extract of the diary, and the pictures that were sent around that same event. This demonstrates that the app allows to collect rich and multi-layered data from a single event in real-time. 
Figure 4: Example of data gathered through the audio diary task complemented with pictures

\begin{tabular}{|c|c|c|c|}
\hline & Pre-match & During match & Post-match \\
\hline $\begin{array}{l}\text { Diary } \\
\text { entries }\end{array}$ & $\begin{array}{l}\text { "Tomorrow afternoon I have a ticket for the away } \\
\text { section for Borussia's away game against VFB } \\
\text { Stuttgart, it will be interesting to compare the } \\
\text { experience with going to many Borussia's away } \\
\text { games in the 1990s, more fans go these days and } \\
\text { the situation is more regulated, the away section is } \\
\text { completely all ticket, but I am entitled to a ticket } \\
\text { because I am a Borussia member. It will be } \\
\text { interesting to see how the organisation of the } \\
\text { game has changed ... DFB regulations for example } \\
\text { on the availability of alcohol, how the German } \\
\text { police, regulate the game, the interaction between } \\
\text { the two sets of supporters before, during and after } \\
\text { the match." }\end{array}$ & $\begin{array}{l}\text { "It's the start of the start of } 2^{\text {nd }} \text { half, Gladbach are } \\
\text { managing to be } 2-0 \text { down with two bad defensive } \\
\text { mistakes ... I've been standing in the standing part } \\
\text { in the away section on the terracing, just as safe in } \\
\text { my opinion as being in the seats but the away } \\
\text { section has got seats above the terracing so you've } \\
\text { got a choice... it's also nice for people to come } \\
\text { around and serve you beer during the game, as a } \\
\text { consequence a lot of the Gladbach fans are drunk, } \\
\text { and noisy, but completely non-violent, and it's } \\
\text { interesting that the sections just to either side of } \\
\text { the guest [away] block, are the sections of the } \\
\text { ground where the Stuttgart fans have chosen not } \\
\text { to sit." }\end{array}$ & $\begin{array}{l}\text { "I think the whole experience was positive... from } \\
\text { the point of view of a spectator, the facilities were } \\
\text { excellent, the stewarding was friendly, there was a } \\
\text { large police presence but they were very relaxed } \\
\text { and didn't interfere with anything ... it's something } \\
\text { that could be slightly more modern, the view was } \\
\text { good, you can sit or stand where you wanted to, } \\
\text { the atmosphere in the ground was very loud, but } \\
\text { very friendly, the supporters all mixed before and } \\
\text { after the game ... before and after the game there } \\
\text { were no problem at all, virtually everybody in } \\
\text { colours, young, old, there was a much higher } \\
\text { proportion of women and youngsters than at your } \\
\text { average equivalent Premiership match in the UK." }\end{array}$ \\
\hline Photos & $\begin{array}{l}\text { Tag: "What football means to me" } \\
\text { Comment: "Home stadium" } \\
\text { Importance: } 7 / 10\end{array}$ & $\begin{array}{l}\text { Tag: "The state of football today" } \\
\text { Comment: "Being served beer at your seat" } \\
\text { Importance: 10/10 }\end{array}$ & $\begin{array}{l}\text { Tag: “Football traditions" } \\
\text { Comment: "Fanprojekt [supporters club] involved } \\
\text { in away games" } \\
\text { Importance: } 10 / 10\end{array}$ \\
\hline
\end{tabular}




\section{Reflecting on the experience: Challenges, weaknesses and strengths of}

\section{an app in qualitative research}

The article moves now to a reflection of the whole process. We discuss our experience by dividing, for heuristic reasons, issues into three themes: the challenges, the weaknesses and the strengths of using an app. The added value of this reflective account is that we take into consideration a second phase of data collection that, whilst having exactly the same objectives and methodology, did not use the app for data collection.

The ugly: Challenges of using an app

Limiting exclusion

Any research study considering the use of an app needs to acknowledge its exclusionary nature. If this is the sole tool used, participants must own a smartphone (and be knowledgeable and confident to use it). This restricts the research to smartphone users and creates a limited and self-selecting sample (Chen, 2011; Killingsworth and Gilbert, 2010; MacKerron and Mourato, 2013). For example, smartphone ownership in the USA is currently at $58 \%$ but is more common for the under 50s, people living in an urban rather than rural area, and is positively correlated with level of education and household income (Pew Research, 2014). Although smartphone ownership continues to increase, it could be argued that this type of technology is always likely to appeal more to certain groups of society than to others. 
This has been described as 'the second level digital divide', with Hargittai (2002) suggesting that although the access gap may be narrowing, the skills gap might be widening. Who is sampled, sampling strategies, and what can be said from the actual sample within a study in terms of data saturation or naturalistic generalisability therefore needs careful consideration. Addressing exclusion relates not just to the use of apps but is equally applicable to a variety of digital tools and methods. Embedding technology into research necessitates the acceptance of the exclusion of some individuals due to the physical and non-physical resources required.

Limiting the exclusionary nature of this type of research is a major challenge. This is particularly the case if the aim is to engage a particular demographic of participant. For example, research using smartphones is less useful for gaining knowledge about the elderly or those with a low income level, so less will be understood about their social worlds. Sonck and Fernee (2013) attempted to overcome this by providing smartphones to participants who did not own one. However this would be costly and a lack of knowledge can cause more difficulties for inexperienced users, affecting the results gained (Fernee, Sonck and Scherpenzeel, 2013). It is also worth considering that the actual type of smartphone owned may exclude some participants. Our app was available for Android and iOS (Apple) systems only, representing the majority of the smartphone market at the time of recruitment but preventing those with Blackberry or Windows phones using the app. Others have noted the difficulty in creating apps across different operating systems (MacKerron and Mourato, 2013). 
For the FREE project it was decided that app usage was optional and was not a prerequisite for taking part in the study. Cameras and voice recorders were provided to non-app users, and the methodology was described in exactly the same way. In this sense there was little difference between smartphone owners and non-owners in terms of recruitment. Two Blackberry owners were unable to use the app but used their phone to take and email pictures. Some participants used their own camera, and others used one provided by us. Provision was made to prevent anybody from being excluded on grounds of equipment ownership (whilst remembering that ownership does not equal technical ability or confidence). This decision facilitated inclusion but inevitably created a number of considerations regarding consistency. Did those with extra equipment take fewer photos? Would they be less likely to carry it with them? In limiting exclusion by providing for smartphone and non-smartphone owners, one of the main benefits of using an app - a streamlined and more time-efficient data collection process - is negated to some extent as non-app users had to be 'chased' more for their contributions.

Balancing 'maximum' data with 'ease of use'

The app had the capability to ask users to perform various tasks. We wanted to take advantage of the fact that once participants had uploaded an image, they could be asked follow-up questions to capture their immediate reaction rather than asking them to reflect at a later date. Also, because we were not asking for specific images, but the vague topic of 'football', it was useful to ask for a tag. But there were many 
more possibilities available to us. The challenge with the technology is not how to make the most of it, but how to balance what can be done whilst retaining an accessible, useable approach.

When designing the script, retaining focus on this balance and prioritising usability for the participant was a challenge. We would highly recommend piloting any app several times as changes are made, as this was very useful for assessing how everything worked on the small mobile screen. Feedback suggested that at times there were too many options on the home screen, and the length of some questions required scrolling, so adjustments were made to try and enhance usability. In this respect, the need for scrolling should be limited as far as possible; for each page, the information provided should fit neatly on the smallest of screens. Qualitative researchers must accept that there is a trade-off between the depth of information that can be gained through an app and the functional usability for participants.

\section{Adequately preparing participants}

Whilst this may be an issue with any data collection tool, adequately preparing participants was a particularly difficult challenge for a project utilising new technologies. Meeting participants to explain how the app works would give the most thorough introduction to the technology, and allow questions to be asked and tasks practiced. This has been employed by researchers undertaking audio-visual methods, to ensure participants are sufficiently briefed and familiar with the devices (Bolger, Davis and Rafaeli, 2003; Duke, 2012; Williamson et al, 2011). However one of the 
benefits of using smartphones is being able to easily access and include a geographically diverse sample (MacKerron and Mourato, 2013; Patel et al, 2013); if researchers are required to meet with participants, this would be negated, or at least it would make it costly. It is therefore a challenge to adequately prepare participants without the time consuming and geographically restrictive need for meeting them in person.

This will not be a problem if a pilot or initial interview is undertaken at the start of the project (Holt et al, 2008) as this can be combined with briefing the participant. But if there is no planned contact with participants prior to the project, researchers need to consider carefully how to brief them and information packs may be needed In addition to information about the study and their involvement - and other essential paperwork such as consent forms - this can create an overload of information that may be offputting.

We decided to set up a meeting with all participants prior to the start of the project to brief them about the study, outline what was expected of them and answer any questions they may have. Whilst time consuming and costly, it was felt this would increase the likelihood of participant retention as a face-to-face meeting would allow for any questions to be answered, and a brief demonstration of the app for those using it (although at this point we only had a test version). Where a meeting was not possible, a Skype conversation was held. In that respect, technology facilitates technology as video calls considerably reduce the costs of meeting participants individually. Smartphone users were provided with a 'user guide', produced in 
conjunction with the software company, that included information on using the app and a troubleshooting guide for any potential problems. Those who did not use the app were provided with a similar 'equipment' guide for anything that was loaned to them. All participants (app and non-app users) were provided with an information pack that gave guidance for the different tasks they would be asked to complete which was emailed prior to the face-to-face meeting, so it could be discussed in person.

\section{The bad: Weaknesses of using an app}

Cost

Working with a software company to design an app that was used in the end by 14 participants proved a costly aspect of this project, particularly if calculated per person. The cost included technological support and a helpline for any problems as well as a 'dashboard' where data was uploaded, securely stored and exported when it was needed. Even though we adapted an existing platform rather than design an app from scratch to meet our needs, this still represented a significant financial outlay. Initial cost has been noted by other researchers in the field (Sonck and Fernee, 2013). Patel et al (2013) kept this aspect of their budget low by using students rather than a commercial company to design the app, but acknowledged that this also had its limitations as the software development took longer and they were not able to draw upon the knowledge that an experienced company can bring to the project. 
The cost of the app for this particular project was considered one of its weaknesses, but depending on the study, this may not necessarily be the case. For longitudinal surveys or those with very large numbers of participants, the initial financial outlay becomes more cost-effective as once the software is designed and running, there are little or no costs for extra participants (MacKerron and Mourato, 2013).

One important consideration regarding the cost of the software is that it did save money in other areas. The most significant area where this is evident is in researcher time. Once participants were using the app it was very easy and quick to monitor their activity and progress, compared to the second phase without the app where participants had to be contacted regularly to check progress. Even when we acknowledge that cost is of course a problem in the use of smartphone apps, our experience suggests that it is affordable and we will argue that it is a valuable addition that can increase the cost-effectiveness of qualitative research in the social sciences, increasing the potential for research impact still at very affordable levels.

\section{Technological limitations}

As we opted to modify an existing app rather than design an original one, we were limited to the existing capabilities. One area where a compromise was needed was the length of audio diaries. In our methodology we had proposed 5-10 minutes for each entry, based on previous diary studies (see for example Duke, 2012). It soon became clear that this would be beyond the capabilities of the app due to the time and memory required to upload an audio file of that size. The software company had previously only used clips of 30 seconds. This was deemed too short for an audio diary, 
and a compromise of two minutes was reached. Feedback from participants suggested that two minutes was not long enough, and many diary entries were cut off before completion. Users did have the option of recording additional entries, but these were only thirty seconds each. It is likely that this limitation had an impact on the volume of data received.

There were some other technological limitations that emerged as the project progressed. The app did not have a 'back' button to allow participants to return to the previous screen at any point in the process. This is something that smartphone users often use to navigate browsers and other apps. Therefore any mistakes could not be corrected and once information was submitted there was no opportunity to edit. Perhaps more problematic was the inability for participants to monitor what they had uploaded. The research team could see this on the dashboard, but participants had no way of knowing how many images they had uploaded. This was an issue that users mentioned when asked for feedback. ${ }^{3}$

Apart from the need to adapt to smartphone features such as screen size, the technical problems described here may be a result of the specific software that we used rather than a problem with apps per se. But costs will play a role in determining the capabilities of the software, and it is likely that compromises will always have to be made between what the researchers want to do and what is possible and realistic within the framework of the software being used. We were unable to do exactly what we wanted with the app because of technological restrictions, and so adapted our questions to what the platform was capable of. 


\section{Software user difficulties}

On reflection, the most problematic matter was issues with the app not functioning properly on certain phones. The app was tested on several different phones prior to becoming available to participants, which is important in terms of the usability and reliability of the technology (Duke, 2012; Patel et al, 2013). Testing is an extra layer of work. Despite the successful pilot, once the app was launched a number of participants reported technical difficulties. Dealing with these took much time in terms of communicating between participants and the software company helpline. One participant dropped out in the first week due to this. Some had the problem solved by downloading updates but others had to stop using the app because the issues could not be resolved. Some participants, when shown their images in the photo-elicitation interview, suggested that they had taken and uploaded more than we had received; certainly, one concerning weaknesses is the potential for data to be lost during the upload process.

This should not stop researchers from using apps, but extensive testing would be recommended. Fernee, Sonck and Scherpenzeel (2013) reported more technical issues with their first pilot than their second, and Patel et al (2013) trialled seven iterations of their app before launch (which followed several stages of group and individual testing). Again we return to the issue of cost/time and quality/efficiency trade-off. Reflecting on our own experiences alongside the studies referenced above it appears that the more time invested in testing the app, the more efficient the app so the more time saved on attempting to resolve technical problems. 


\section{The good: Strengths of using an app}

\section{A truly 'mobile' instrument}

The clearest benefit to using a smartphone is that participants can be spontaneous with what they record. This has great potential for qualitative research into people's lives. Smartphone users have (almost) permanent access to their device, so can report multiple times a day, resulting in less recall problems (Fernee, Sonck and Scherpenzeel, 2013). Whilst we encouraged participants to upload whenever they felt like it, the mobile nature of the methodology means that the bleep method can also be used (see for example Sonck and Fernee, 2013) where users are sent a prompt to respond to. An app is not however necessary for this sole benefit to be gained. Any mobile phone with a camera can fulfil this requirement, as images can be submitted either online or by text message.

What an app does add is to be a 'one stop shop' combining the above with a greater depth of data that can be gathered. An image can be accompanied by contextual data, and followed with probing questions (figure 3 above gives examples). This is more difficult to do using just the basic functions of a phone such as email or text messaging. Particularly useful to us was the 'tags' that the photo taker could assign to the image asking for this information at a later date incurs a time lapse, so responses are likely to be more measured and reflective and perhaps even less accurate. Also, allowing users to do audio diaries whilst at events, or on the way home using their phone, provided a more instant and emotive reaction to events than reflective diary entries might. 
Data submission, storage and management

All data uploaded through the app by participants was stored and managed on a web portal. Researchers had instant access to this, so could monitor uploads as they happened. Those who did not use the app were asked to email or upload to a file sharing website, which was a much more time consuming process for both the participant and the researcher. Further, all data submitted through the app was received in the same format, which gave a consistency to the data that was not evident with non-app users.

\section{Monitoring and communicating with participants}

Being able to see data as it was submitted allowed the research team to monitor how participants were progressing over the 6-8 weeks given. It was therefore very clear if any participants were not progressing with the tasks, or whether they went for long periods without uploading any data. Phase two, where the app was not offered, highlighted the value of this as participants were left alone for the duration with no method of monitoring their progress apart from contacting them to check how they were doing, which had to be minimal to prevent from becoming intrusive. App users were aware that they were being monitored, which perhaps encouraged them to take the full time allowed and upload regularly rather than take all of their photos close to the deadline; everything was done in real time. The use of the app certainly gave our participants some self-discipline when completing the tasks. This unintended consequence should not be underestimated (see below). 
The app also allowed for brief communication with participants in the form of notifications. Notifications were sent on Friday evenings reminding participants to take photos or record diaries if they were going to a football match over the weekend. Individual notifications could also be sent if certain participants were not progressing. Similar to the 'bleep' method, notifications could be used to remind people to complete certain tasks at certain times in an attempt to overcome difficulties with traditional diary methods such as forgetfulness or difficulties completing them at the required time (Bolger, Davis and Rafaeli, 2003; Duke, 2012; Holt et al, 2008).

Providing an external time structure

The app had a launch date, when the period of data collection started, and ran for a fixed period of time. Participants were aware of this, were prepared in advance and were ready to download the app on its launch. All began at the same time, and although some finished quicker than others, the app gave the data collection period a strict end date. The benefit of this was not fully understood until the second phase where, without an app, participants were allowed to start their particular time period at a time to suit them. Although this provided flexibility for participants to pick a time when they felt most able to complete the project, and to shift their start date if required, it led to the period of data collection being stretched over a period of four months compared to the two months that the app restricted the first phase to. There is a cost implication of the increased researcher time required to monitor over this extended period. 
Of course a strict time structure could be embedded into the research process without the need for an app. But reflecting on both phases, we feel that the external time structure placed on the project by the app encouraged participants to adhere to this.

\section{Conclusion}

This paper has reflected on the use of a smartphone for collecting qualitative data, a tool that has not been reported on in the academic literature in any length. Technological advances are moving forwards at an alarming rate and in order to capitalise on this to aid the research process, reflection and knowledge sharing is essential.

Smartphone technology for certain purposes can be embraced and integrated into qualitative research; it can enhance the research process. As with any data collection tool, this approach is not without weaknesses. Being transparent about these - and using an app in combination with other methods - can limit their impact on the research. Whilst there are a number of challenges, we strongly believe that smartphones and apps have a huge and still relatively unexplored potential for enhancing the qualitative research process.

What did using an app add to the research experience for us? Whilst we have outlined some benefits above, others are impossible to judge and can only be speculated upon. It was hoped that the app would add fun and interaction to the data collection process, and encourage people to take part and stay involved over the eight weeks. We hoped 
it would not impact too greatly on their time, through being mobile and therefore easily fitted around their normal activities. All of these hopes had two interconnected aims, which could not be met without the other: to maintain the participants' interest for the duration of the project, and to make it enjoyable for them. Feedback from those who used the app - it was functional but also fun to engage with.

But drop-out still occurred, and occurred at a similar rate to those who did not use the app. Why was this? One simple answer is that using an app does not overcome the fact that drop-out occurs in projects where a lengthy time commitment is required, and this drop-out can happen for many reasons that are out of the control of the researcher. Whilst the app made it easier for participants to upload, they still had to fulfil the requirements of the project over eight weeks, quite a commitment. The smartphone app, as a data collection tool, simply aided this.

A more complex answer is the unintended outcome of the fact that participants are familiar with using their phone, and for many of them, apps are part of their daily life. In this respect, the research app may have become just one of many apps that smartphone users engage with. Does using an app make the participant take the study less seriously, as they have not been entrusted with equipment to complete a task? Fernee, Sonck and Scherpenzeel (2013: 6) loaned smartphones to those in their sample who did not own them, and found that those who borrowed had a higher response rate than those who used their own, suggesting 'it may be that respondents using a borrowed smartphone felt more obliged to complete their diary accurately than participants who used their own'. Did our app just become another option of 
something to do on their phone? Did it just blend in to the smartphone? If the same person had been given a camera and asked to take photos, would they have felt more responsibility to oblige? All of this is conjecture, but it is important to consider given that one aim of using a smartphone app might be to increase engagement. A drawback of making the process less intrusive for the participant is that for this same reason it may not be at the forefront of their mind.

It could be concluded that this paper poses more questions about utilising new technologies such as smartphones to collect qualitative data than it gives answers. The research field is so new and under-explored that this should not be surprising. We have offered our reflection of the experience in the hope of stimulating further work. We share two concluding thoughts in particular as suggestions for future debate.

Firstly, it is important to consider whether the data that a smartphone app collects when used in this way can be considered as 'naturalistic' when participants are engaged in a project for a specific purpose. In that sense, it is interesting to consider how this compares with other 'data' that smartphones generate when users are engaging with social media sharing sites such as Facebook or Twitter. Uploads through these sites are also user-generated, instant and rich data forms that give an insight into a particular social world or experience. As we only collected user-prompted data for this study we cannot make comparisons with other forms of shared digital data but we would encourage others to consider this in relation to the type of data that a smartphone app collects. 
Secondly, we considered the smartphone as a technical tool through which to collect qualitative data. For us, it was an instrument that we perceived as disconnected from the experience it was capturing, and therefore also the user capturing it. Yet the smartphone could also be conceptualised as embedded within the reality of the social world that it is tasked with capturing. This would alter the perspective of an app as an objective tool to one that creates rather than reflects the social world under investigation, and have implications for both the design of an app and the data collected. Again, this is beyond our reflective discussion of the process of using the app but we highlight these two conclusions as interesting areas that we encourage qualitative researchers to consider further.

\section{Acknowledgements}

The authors would like to thank the three anonymous reviewers for their constructive comments on the first draft of this article. We also would like to acknowledge Crowdlab for their help in developing the smartphone app used in this research and especially Richard Owen and Niall Smith for their comments on this article's reflections.

\section{Funding}

This work was supported by the European Commission's 7th European Framework Programme for Research (FP7) [grant agreement 290805]. 


\footnotetext{
${ }^{3}$ The software company responded to feedback on these technical issues, and have since addressed many of the problems that our participants faced. In particular, participants now have access to their own online portal where they can monitor what they have uploaded, allowing them to notice any gaps and track their own submissions.
} 


\section{References}

Aanensen, D., Huntley, D., Feil, E., al-Own, F and Spratt, B (2009). EpiCollect: Linking smartphones to web applications for epidemiology, ecology and community data collection. PLOS ONE 4(9). Available online at: http://www.plosone.org/article/info\%3Adoi\%2F10.1371\%2Fjournal.pone.0006968 (accessed 12 May 2014).

Bolger, N, Davis, A and Rafaeli, E (2003). Diary methods: Capturing life as it is lived. Annual Review of Psychology, 54: 579-616.

Bouwman, H., Heerschap, N. and de Reuver, M. (2013). Mobile handset study 2012: Evaluation of mobile measurement software to monitor the use of smartphones and tablets in the Netherlands. Delft/Den Haag: Statistics Netherlands and Delft University of Technology.

Chen, G (2011). Mobile research: Benefits, applications and outlooks. In Internationalization, Design and Global Development, Part 1, pp.11-16. Available online at: http://download.springer.com/static/pdf/310/chp\%253A10.1007\%252F978-3-642$\underline{21660-}$

\section{2.pdf?auth66=1408703356 f0c0fba7af4bf1ebb780538890663ba7andext=.pdf} (accessed 12 May 2014). 
Cherrington, J and Watson, B (2010). Shooting a diary, not just a hoop: Using video diaries to explore the embodied everyday contexts of a university basketball team. Qualitative Research in Sport and Exercise, 2(2): 267-281.

Day, M., \& Thatcher, J. (2009). 'I'm really embarrassed that you're going to read this ...': Reflections on using diaries in qualitative research. Qualitative Research in Psychology, 6: 249-259.

Deloitte (2013). Beyond the hype: The true potential of mobile. Deloitte: London.

Dennison, L, Morrison, L, Conway, G and Yardley, L (2013). Opportunities and challenges for smartphone applications in supporting health behaviour change. Journal of Medical Internet Research, 15(4): 86.

Duke, J (2012). Joining the dots: Piloting the work diary as a data collection tool. Issues In Educational Research, 22(2): 111-126.

Edison Research (2014). 2014 smartphone ownership demographics. Available at: http://www.edisonresearch.com/2014-smartphone-ownership-demographics/ (accessed 26 September 2014). 
Fernee, H, Sonck, N and Scherpenzeel, A (2013). Data collection with smartphones: Experiences in a time use survey. New Techniques and Technologies for Statistics 2013, Brussels, 5-7 March 2013.

Hargittai, E. (2002). Second level digital divide: differences in people's online skills. First Monday, $\quad$ 7(4). Available online at: http://firstmonday.org/htbin/cgiwrap/bin/ojs/index.php/fm/article/view/942/864 (accessed 30 September).

Holt, N.L, Tamminen, K.A, Black, D.E, Sehn, Z.L and Wall, M.P (2008). Parental involvement in competitive youth sport settings. Psychology of Sport and Exercise, 9: $663-685$.

Killingsworth, M. A. and Gilbert, D. T. (2010). A wandering mind is an unhappy mind. Science, 330: 932.

Kiukkonen, N, Blom, J, Dousse, O, Gatica-perez, D and Laurila, J (2010). Towards rich mobile phone datasets: Lausanne data collection campaign. In Proceedings of the 7th International Conference on Pervasive Services. Available online at: http://www.idiap.ch/ gatica/publications/KiukkonenBlomDousseGaticaLaurilaicps10.pdf (accessed 12 May 2014). 
Luxton, D, McCann, R, Bush, N, Mishkind, M and Reger, G (2011). mHealth for mental health: Integrating smartphone technology in behavioral healthcare. Professional Psychology: Research and Practice, 42(6): 505-512.

MacKerron, G and Mourato, S (2013). Happiness is greater in natural environments. Global Environmental Change, 23 (5): 992-1000.

Ofcom (2014). Media: Facts and figures. Available online at: http://media.ofcom.org.uk/facts/ (accessed 30 September 2014).

Patel, V, Nowostawski, M, Thomson, G, Wilson, N and Medlin, H (2013). Developing a smartphone 'app' for public health research: The example of measuring observed smoking in vehicles. Journal of Epidemiology and Community Health, 67: 446-452.

Patton, M (1990). Qualitative evaluation and research methods. London: Sage.

Payne, K, Wharrad, H and Watts, K (2012). Smartphone and medical related App use among medical students and junior doctors in the United Kingdom (UK): A regional survey. BMC Medical Informatics and Decision Making, 12: 121-132.

Pew Research (2014). Cell phone and smartphone ownership demographics. Available online at: http://www.pewinternet.org/data-trend/mobile/cell-phone-andsmartphone-ownership-demographics/ (accessed 26 September 2014). 
Plowman, L and Stevenson, O (2012). Using mobile phone diaries to explore children's everyday lives. Childhood, 19(4): 539-553.

Raento, M, Oulasvirta, A and Eagle, N (2009). Smartphones: An emerging tool for social scientists. Sociological Methods and Research, 37(3): 426-454

Sonck, $\mathrm{N}$ and Fernee, $\mathrm{H}$ (2013). Using smartphones in survey research: $A$ multifunctional tool. The Netherlands Institute for Social Research, The Hague, July 2013.

Sparkes, A.C and Smith, B (2014). Qualitative Research Methods in Sport, Exercise and Health: From process to product. London: Routledge.

Tamminen, K.A and Holt, N.L (2010). Female adolescent athletes' coping: A seasonlong investigation. Journal of Sports Sciences, 28(1): 101-114.

We Are Apps (2013). UK Mobile Insights Report 2013 Q4. Available online at: http://weareapps.com/MobilelnsightsReport.pdf (accessed 14 May 2014).

Welford, J, Garcia, B and Smith, B (2015). A 'healthy' future? Supporters' perceptions of the current state of English football. Soccer and Society, 16(2-3): 322-343. 
Williamson, I, Leeming, D, Lyttle, S and Johnson, S (2011). 'It should be the most natural thing in the world': Exploring first-time mothers' breastfeeding difficulties in the UK using audio-diaries and interviews. Maternal and Child Nutrition, 8: 434-447. 